latter area in the Iron Age. Iron was introduced into Northern India by the Vedic Arya about 1500 B.C., who drove the previous inhabitants towards Central and Southern India, where the 'black' metal and the horse are associated with invaders from the north.

Prehistoric skeletal remains fall into two groups, (a) the calcholithic, from the Indus Valley, especially Mohenjo-daro and Harappa; and (b) Iron Age.

The majority of the skeletal remains of the calcholithic Indus valley civilisation are dolichocranial, but show evidence of two long-headed races, of which one has a much larger skull, but with lower cranial vault and marked post auricular development. At first classed as Proto-Australoid, it is now regarded as 'Caucasic'. A third race, most strongly represented at Harappa, is brachycephalic, showing Armenoid affinities.

The skulls of the scanty Iron Age remains show Australoid, Mediterranean and Armenoid affinities. It is suggested that late in the Iron Age the Peninsula was occupied by a long-headed high-skulled race with a low broad face, comparable to the Combe Capelle type, and further that this type is to be associated with the megalithic culture. Apparently it absorbed a negrito element and later had superimposed on it a race with Armenoid affinities.

The racial history of the Indian peoples may then be summarised as follows :

At the beginning of the fourth millennium B.C., Northern India was occupied by a long-headed race with high cranial vault and long narrow face, by its side being a second, powerfully built, race, also longheaded, but with distinctive peculiarities. With these was a third race showing Armenoid affinities, probably a later influx. None of these had as yet penetrated Southern India. Possibly as early as the neolithic age the megalithic culture had been introduced by people of the Combe Capelle type, who afterwards in the Iron Age reached Southern India, where they subdued the aborigines, but themselves were overrun later by people of Armenoid affinities. In the north they mingled with the Mediterraneans of the Indus Valley to form the bulk of the population of Peninsular and Northern India of to-day. In the upper classes of Northern India another strain, with undoubted northern affinities, is clearly to be distinguished, which, as E. Fischer says, retains the Nordic characters, but without the fair tint of the skin. This strain in fact is also retained slightly among Tamil Brahmins in the south; but it is especially evident among the Chitpavan, or Maharashtra, Brahmins, who constitute one of the fairest groups in India. It is probable that the powerfully built large-headed strain at Mohenjo-daro forms one of the constituents of this race, whose advent to India appears to synchronise with the 'Aryan' invasion.

The brachycephalic element dominant in the west and south-west of India and also in Bengal to-day, which is definitely non-Mongolic in character, possibly drifted into Bengal before it reached Southern India. Its occurrence at Mohenjo-daro and Harappa is definitely against the view that it is a Tokharianspeaking race from the Pamirs. It is comparable to the brachycephalic element in southern Arabia, which Keith identified in the records of Bertram Thomas.

\section{The Upper}

$\mathrm{I}^{\mathrm{N}}$ the Joule Memorial Lecture delivered to the Literary and Philosophical Society of Manchester on February 11, Prof. E. V. Appleton said that it was perhaps not inappropriate, in a lecture associated with a great pioneer in thermal measurements, to survey recent advances in our knowledge concerning the temperature of the upper air. Frictional work produces heat, as is well known, and Joule was the first to state the exact nature of this equivalerree. An example of the heating process studied by Joule is the flight of a meteor through the atmosphere, in which case the energy of its speed is ultimately transformed into heat and light. But it has been found that electric waves can also heat the atmosphere when they travel through it. Ultra-violet light from the sun, for example, produces a belt of hot air at about the level in the ionosphere $(300 \mathrm{~km}$. high) where short wireless waves are reflected. It has also been found that a powerful long-wave wireless station can warm up the Kennelly-Heaviside layer to a very small but still detectable extent. The so-called 'Luxembourg effect' noticed by long-distance listeners, who find that they receive a long-wave programme when their receiver is tuned to the medium waves, can be traced to the influence of such a process.

It is a familiar fact that the temperature of the air falls as we go upwards from sea-level. But the temperature does not go on decreasing, as Teisserenc de Bort first showed by experiments with free

\section{Atmosphere}

balloons. At a height which varies from $16 \mathrm{~km}$. at the equator to $6 \mathrm{~km}$. at the poles, the fall of temperature is arrested. It is at this level that the stratosphere begins, the underlying stratum being called the troposphere.

At first it was assumed that the stratospheric temperature of $-53^{\circ} \mathrm{C}$. is maintained up to the highest levels, and it eame as quite a shock when Lindemann and Dobson announced, in 1922, that their study of the tracks of meteors in the atmosphere had led them to conclude that the air at $60 \mathrm{~km}$. in height must be $30^{\circ}$ C.- a temperature higher even than that obtaining at ground-level. Experiments on the anomalous propagation of sound from explosions and gunfire had shown that sound waves were reflected at this warm level. The sound of a gun at Shoeburyness, for example, would be expected to travel to Birmingham in a little more than ten minutes and yet the measured time, due to the upperair trajectory pursued by the waves, was found to be twelve minutes.

In the electrically conducting region of the atmosphere, the daily sequence of events has been studied by means of radio-wave exploration. Conditions do not change much from summer to winter at the $100 \mathrm{~km}$. level, but there appears to be a very pronounced seasonal variation of temperature at $300 \mathrm{~km}$. In summer the ionisation at that level is abnormally low, whereas theory would suggest that it should be 
twice the winter value. The discrepancy has been traced to the effect of solar heating which causes the air to expand. The expansion, in turn, dilutes the electrical concentration proportionally with the reduction of air density.

It may, at first sight, seem impossible for human beings to be able to affect conditions at high levels, and yet it has recently been found that powerful wireless stations can increase to a very small extent the temperature of the Kennelly-Heaviside layer. Due to the modulation of such a station, the slight heating varies rhythmically with the speech or music being transmitted and the programme is, as it were, stored up in the absorptive properties of the layer. The effect of this is most unfortunate, for any other waves reflected at the affected patch acquire the modulation of the unwanted programme. The result is that listeners may find an undesired programme obtruding when they are listening to a station on quite a different wave-length. The practical consequence of this so-called 'Luxembourg effect' appears to be that until it is possible to reduce the upward radiation towards the Kennelly-Heaviside layer, there is a certain amount of danger in increasing the power of long-wave broadcasting stations beyond a certain limit.

\section{Effect of Fog upon Plant Growth}

$\mathrm{O}$ ING to the severe damage caused by London fogs to orchid flowers, begonias and other plants at the Royal Botanic Gardens, Kew, experiments have been carried out at Kew during the past few months with (1) ammonia, (2) electric fans. These experiments were described by Sir Arthur Hill at the Linnean Society on January 30. A 2 per cent solution of ammonia was placed in trays on the floor of the house where begonias, "Gloire de Lorraine", etc., were in flower, with the object of neutralising the sulphuric acid present in the fogs. Very little shedding of flowers or leaves took place beyond what is normal at this season. Electric fans were installed in the Tropical Begonia and Tropical Orchid Houses, and proved quite successful during the bad fogs in December 1935. Calanthe flowers remained uninjured, whereas in an adjoining similar house without fans all the flower spikes were seriously damaged and blackened.

During the bad fogs in mid-January, however, when snow fell at the same time, the fans were not so effective, and it seems probable that the humidity of the houses was unduly high at the time and the fans ceased to lower the humidity, so that the injurious matters in the fog were able to be effective. It seems clear from the experiments carried out so far that the fog damage is elosely linked with temperature and moisture conditions, and immunity can only be effected by careful adjustment of these two factors.

Specimens of Calanthe influorescence were shown at the meeting, some entirely blackened and wholly spoilt, some with the older buds injured, others fairly normal.

Dr. C. R. Metcalfe made microscopical examinations of the leaves which fell in the houses unprovided with fans or ammonia. $\mathrm{He}$ finds that when leaves of begonias and other plants fall off during foggy weather, the petioles sometimes break where an absciss layer is present, but in other instances an irregular fracture occurs. No evidence has been found that foggy weather stimulates the formation of absciss layers. Granular material, which stains readily with alkannin, tends to accumulate at the points where the leaves break off.

\section{Bicyclic Terpenes}

$\mathrm{I}^{\mathrm{N}}$ his presidential address to the Chemistry Section of the twenty-third Indian Science Congress held at Indore on January 2-8, Dr. P. C. Guha reviewed at length recent developments in the chemistry of the bicyclic terpenes, derivatives of camphane, santane, pinane, thujane and carane being reviewed in turn.

Apart from the very obvious importance of a detailed study of natural products, one of the most interesting developments in recent years has been to widen the scope of stereochemical problems. Thus the study of decalin (decahydronaphthalene), the parent hydrocarbon of the sesquiterpenes, led Hückel to the discovery of a new type of stereoisomerism arising out of the cis and trans interlockings of two monocyclic structures to multiplanar molecules. This work and that of Ruzicka on the stability of poly. membered carbon rings have provided strong arguments against Baeyer's uniplanar models for cyclohexane and higher carbon rings; but in discussing the work of Linstead and Barrett on the bicyelo- octanes, the author has overlooked the fact that the multiplanar configurations assigned by Hückel to the decalins and hydrindanes have been conclusively confirmed recently by the discovery of the existence of optical isomerism in certain of their derivatives.

The interesting reaction described by Diels and Adler in 1928, in which a conjugated system of double bonds is caused to combine additively in the 1.4 positions with compounds containing the grouping $-\mathrm{CH}=\mathrm{CH}-\mathrm{CO}-$, has opened the way to the synthesis of many bicyclic terpene derivatives, including camphor compounds, and the systematic study of the degradation products in the fenchane and camphane series has progressed steadily. A new type of intramolecular rearrangement has been described by Nametkin in which $\alpha$-methylcamphene on hydration yields 4-methylisoborneol instead of the 6-methylisomer which would be expected from the usual Wagner mechanism. The published address (Calcutta: Asiatic Society of Bengal) includes a useful classified bibliography. 